
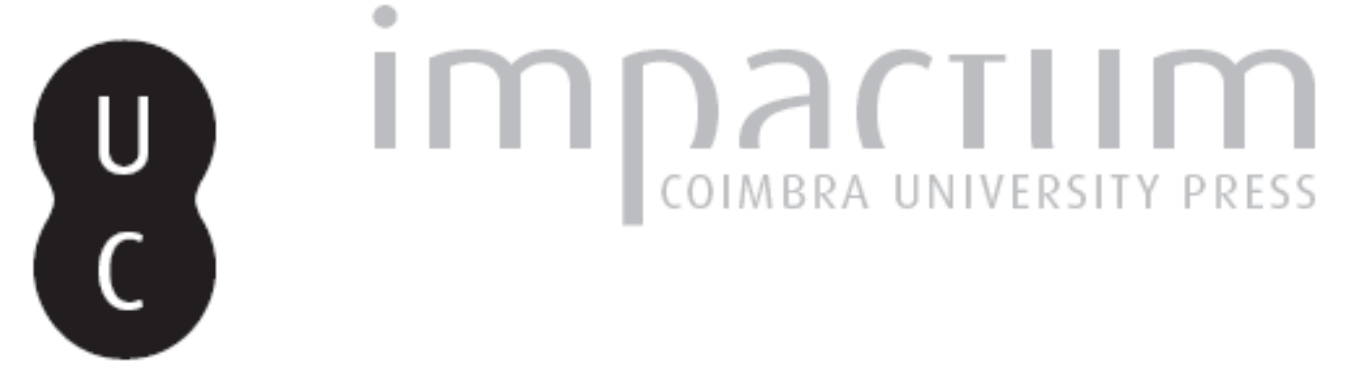

\title{
Entre público e privado, entre a metrópole e o Império: testamentos nas misericórdias portuguesas (séculos XVI-XVII)
}

Autor(es): $\quad$ Fernandes, João Miguel

Publicado por: Imprensa da Universidade de Coimbra

URL persistente:

URI:http://hdl.handle.net/10316.2/40686

DOI:

DOI:https://doi.org/10.14195/0870-4147_47_11

Accessed : $\quad$ 26-Apr-2023 11:58:08

A navegação consulta e descarregamento dos títulos inseridos nas Bibliotecas Digitais UC Digitalis, UC Pombalina e UC Impactum, pressupõem a aceitação plena e sem reservas dos Termos e Condições de Uso destas Bibliotecas Digitais, disponíveis em https://digitalis.uc.pt/pt-pt/termos.

Conforme exposto nos referidos Termos e Condições de Uso, o descarregamento de títulos de acesso restrito requer uma licença válida de autorização devendo o utilizador aceder ao(s) documento(s) a partir de um endereço de IP da instituição detentora da supramencionada licença.

Ao utilizador é apenas permitido o descarregamento para uso pessoal, pelo que o emprego do(s) título(s) descarregado(s) para outro fim, designadamente comercial, carece de autorização do respetivo autor ou editor da obra.

Na medida em que todas as obras da UC Digitalis se encontram protegidas pelo Código do Direito de Autor e Direitos Conexos e demais legislação aplicável, toda a cópia, parcial ou total, deste documento, nos casos em que é legalmente admitida, deverá conter ou fazer-se acompanhar por este aviso.

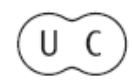




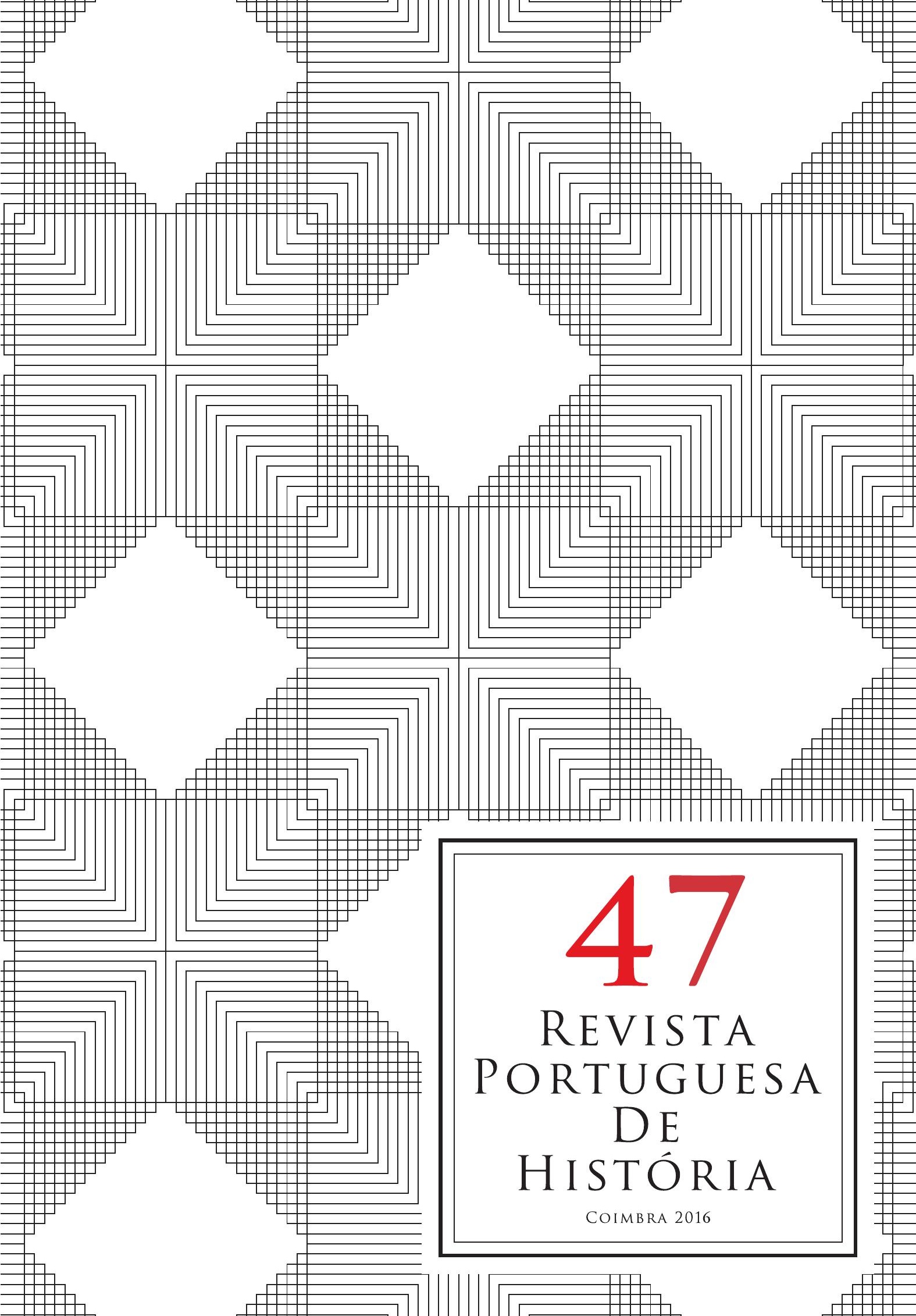




\title{
Entre público e privado, entre a metrópole e o Império: testamentos nas misericórdias portuguesas (séculos XVI-XVII)
}

\author{
Between public and private, between Portugal and the Empire: \\ testaments in the Portuguese Misericórdias (16th-17th centuries)
}

\author{
Jõ̃o Miguel FERNANDES \\ Universidade do Minho \\ joaomiguelfernandes12@gmail.com
}

Texto recebido em/Text submitted on: 31/01/2016

Texto aprovado em/Text approved on: 22/06/2016

\section{Resumo:}

O presente trabalho pretende contribuir para a compreensão da forma como as misericórdias estabeleciam a ligação entre defuntos e ausentes e as suas terras de proveniência. Para isso, os testamentos apresentam-se como o primeiro passo para compreender o processo de transferência de bens, sendo importante perceber o enquadramento legal subjacente a este tipo de documentação, sobretudo no que respeita às diferentes modalidades existentes e a algumas situações de exceção. Embora o ato de testar fosse privado por natureza, o número e a diversidade de instituições envolvidas contribuía para lhe conferir um caráter público, uma vez que para além dos notários, nomeados pelo rei, outras instâncias se imiscuíam nos processos a que os testamentos davam origem. A Coroa criou uma figura que teria como principal função fazer cumprir as últimas vontades dos defuntos - o provedor dos defuntos e ausentes. Este oficial régio tinha legislação específica que norteava a sua intervenção. Neste campo, a ação das Misericórdias também se revelou fundamental. Efetivamente, as Santas Casas, com o intuito de fazerem cumprir os legados que lhe eram
Abstract:

This article aims to broaden our understanding of the ways in which the Misericórdias connected the Portuguese who had emigrated overseas to their families that had remained in Portugal. Even if they could write to them for other matters, their utmost concern was the transfer of property, which occurred mainly after death. Last wills were thus the main vehicle for such transfers. The first step to understand this subject is to study the legal framework that ruled the elaboration of testaments, especially in what concerns their typology and casuistic. Although the act of testing was private in nature, the number and diversity of institutions involved contributed to give it a public character, since in addition to notaries, appointed by the king, other institutional instances interfered on the processes that wills gave rise to. Also concerning the legal framework, it is important to know the role played by the provedor dos defuntos e ausentes - a royal official that supervised the execution of testaments and the safeguard of the assets of the dead. The Misericórdias also collaborated in those procedures, by creating a correspondence 
atribuídos, instituíram um sistema funcional complexo, onde a cooperação entre elas assumia particular relevância.

Palavras chave:

Império Português; Misericórdias; Testamentos; Provedoria dos Defuntos network that connected the different parts of the Portuguese Empire, and also acting as proxy to the dead.

Keywords:

Portuguese Empire; Misericórdias; Last wills; Transfers of property.

\section{Introdução}

Ao longo do período moderno, as misericórdias desempenharam um papel fundamental nas comunicações entre os portugueses que viviam nas colónias e a metrópole, sobretudo através da sua ação como provedoras de defuntos. O meio utilizado foi geralmente a correspondência entre elas, que passava obrigatoriamente pela Misericórdia de Lisboa. As cartas tinham normalmente por assunto a transmissão de propriedade a parentes ou a misericórdias do continente; não só os portugueses que foram para as colónias testavam a favor dos seus parentes e das próprias misericórdias metropolitanas, como podiam por vezes enviar somas em dinheiro ou simples cartas. As primeiras deixaram rasto nos arquivos uma vez que o dinheiro dava entrada nos cofres e era registado; destino diferente tiveram as cartas a parentes, que foram entregues aos seus destinatários. Esta valência das misericórdias tem sido ainda pouco visitada pela historiografia, quer por aquela que se debruça sobre estas confrarias, quer pela respeitante a Portugal e ao seu império. Os estudiosos autores de monografias sobre misericórdias têm detetado estes processos relativos à correspondência e execução de testamentos de portugueses falecidos além-mar, geralmente disponíveis em pequenas quantidades para cada misericórdia; e têm-nos referido nos seus trabalhos, embora não lhes atribuam centralidade, por várias razões. Até agora, existe um único estudo específico sobre esta temática, da autoria de Inês Amorim, relativo às cartas da Índia existentes nas fontes pertencentes à Misericórdia de Aveiro' .

Os testamentos eram pedras basilares em todo este processo, uma vez que o principal assunto destas cartas era a transmissão de bens dos defuntos, dando origem a processos de transferência de propriedade complexos e morosos. Embora o ato de transmitir propriedade a parentes ou amigos seja

\footnotetext{
${ }^{1}$ Inês Amorim, “A Misericórdia de Aveiro e as Misericórdias da Índia do século XVII Procuradoras dos Defuntos", in Actas do Congresso Internacional do Barroco, Vol. I, Porto, Universidade do Porto, 1991, p. 113-139.
} 
de natureza privada e íntima, testar tornava-se um ato de caráter público, sendo objeto de legislação específica, implicando testemunhas e o recurso a um notário. Os testamentos são fontes importantes para perceber as atitudes perante a morte, as relações familiares e sociais, os afetos, e a cultura material da época. É importante salientar que a difusão do testamento está ligada ao papel desempenhado pela Igreja Católica, que procurou incutir nos seus fiéis a noção de que após a morte haveria um julgamento final onde seria decidido o destino da alma. Assim, os testamentos tornaram-se instrumentos utilizados pelos crentes para garantir a salvação eterna. Como defende Philippe Ariès, a expressão das últimas vontades foi um meio religioso e quase sacramental de colocar as riquezas ao serviço da obra pessoal da salvação da alma². Não se trata de uma questão de somenos importância, dado que as almas passaram a integrar uma esfera específica, a da jurisdicidade, que as transformava em herdeiras. ${ }^{3}$ Através deste tipo de documentos podemos discernir os próprios anseios dos testadores; o primeiro, e claramente o mais importante, era garantir a entrada no paraíso através de um abreviamento dos tempos de penitência no Purgatório. As misericórdias cedo absorveram doações entre vivos e post-mortem, que tinham como principal contrapartida a celebração de missas por alma, ou a caridade para com os pobres, igualmente eficaz do ponto de vista escatológico ${ }^{4}$.

Mas para além de ser um "passaporte para o céu"s, o testamento constituía também meio de transmissão de riqueza, originando por isso tensões que requeriam enquadramento jurídico adequado. É por aqui que começamos o nosso trabalho, através de uma análise da legislação que regia a feitura de um testamento. Assim, discriminaremos as várias modalidades testamentárias existentes, e as condições preconizadas por cada uma delas.

Em seguida, uma vez que o nosso objetivo consiste em compreender como eram cumpridas as últimas vontades dos que morriam nos territórios da expansão portuguesa, apresentaremos sumariamente a figura do Provedor dos Defuntos, no sentido de saber quais eram as suas obrigações, e o seu raio de atuação. Dadas as particularidades que a Provedoria dos Defuntos assumiu no Estado da

${ }^{2}$ Philippe Ariès, Sobre a História da Morte no Ocidente desde a Idade Média, Pedro Jordão (trad.), Lisboa, Teorema, 1989, p. 116.

${ }^{3}$ Maria de Lurdes Rosa, As almas herdeiras : fundação de capelas fúnebres e afirmação da alma como sujeito de direito (Portugal, 1400-1521), Lisboa, Universidade de Lisboa, 2005, p. 11.

${ }^{4}$ Isabel dos Guimarães Sá, "Catholic Charity in Perspective: The Social Life of Devotion in Portugal and its Empire (1450-1700)", e-Journal of Portuguese History, vol. 2 number 1, (2004), (http://hdl.handle.net/1822/23296, consultado em 2016.01.23).

${ }_{5}^{5}$ Jacques Le Goff, A civilização do Ocidente Medieval, vol. I, Lisboa, Editora Estampa, 1983, p. 232. 
Índia, focaremos em especial a centralidade que a Misericórdia de Goa ocupou neste processo, bem como a orgânica funcional da transmissão de propriedade entre os territórios da expansão portuguesa e a metrópole.

\section{O testamento: modo de usar}

O Direito Civil Romano regulou o ato de testar com o objetivo de impedir fraudes, definindo as "solenidades" externas e internas". O testador tinha o poder e liberdade de dispor dos seus bens; o testamento não era imutável, podendo ser alterado e mesmo revogado. Após a morte do testador, as suas últimas vontades teriam de ser escrupulosamente cumpridas pelos testamenteiros, pessoas da sua confiança, expressamente designadas pelo próprio, que estavam incumbidas de cumprir a sua vontade. Assim, e apesar de as Ordenações Afonsinas ${ }^{7}$, bem como as Manuelinas ${ }^{8}$ versarem esta temática, as Ordenações Filipinas legislaram-na de uma forma mais detalhada.

Torna-se relevante também salientar o papel da Igreja na difusão dos testamentos. Encarada como intermediária entre os homens e Deus, a Igreja defendia que a realização do testamento era um ato fundamental para garantir a salvação'. Consequentemente, pugnava pela sua feitura atempada; mulheres próximas do parto eram exortadas a fazê-lo, bem como qualquer pessoa que estivesse prestes a enfrentar uma batalha, ou uma longa e arriscada viagem. Em último recurso, o sacramento da extrema unção revelava-se uma excelente oportunidade para sensibilizar o crente. Esta influência da Igreja, muitas vezes beneficiária dos próprios testamentos, gerou tensões que desembocaram na criação de legislação específica com o intuito de reduzir a sua influência. Certo é que os testamentos ajudam a explicar o fortalecimento do poder eclesiástico, materializado no enriquecimento de igrejas, irmandades, capelas e mosteiros; mas também é verdade que os poderes senhoriais e régios tentaram obter capacidade de intervenção na sua feitura e execução.

${ }^{6}$ Margarida Durães, Herança e sucessão. Leis, práticas e costumes no termo de Braga (séculos XVIII e XIX), vol. I, Braga, Universidade do Minho, 2000, p. 49.

${ }^{7}$ Ordenações Afonsinas, Livro IV, Títulos 84, 95, 86, 87, 101 e 103.

${ }^{8}$ Ordenações Manuelinas, Livro IV, Títulos 80, 84, 86, 87.

${ }^{9}$ Margarida Durães, "Uma Primeira Aproximação aos testamentos: Venade e Prática de testar da sua população" in Rui Feijó, Herminio Martins, João de Pina Cabral, A Morte no Portugal Contemporâneo - Aproximações Sociológicas, Literárias e Históricas, Lisboa, Editorial Querco, p. 165. 
Como nos diz Ana Cristina Araújo, "o testamento atravessa verticalmente a sociedade" ${ }^{10}$; contudo, incide de uma forma mais intensa nos extratos sociais superiores, uma vez que são aqueles com patrimónios mais avultados. Existiam também alguns subgrupos que a lei impedia de testar ${ }^{11}$ : neles se inseriam os homens menores de 14 anos e as mulheres com idade inferior a 12 anos. Por outro lado, os "furiosos ou mentecaptos" também estavam proibidos de o fazer, exceto se tivessem momentos de lucidez. A todos portanto se requeria "perfeito juízo", condição sine qua non da validade de qualquer testamento. Também os filhos-pródigos e os filhos-família que ainda viviam sob o jugo do poder paternal não podiam testar, a não ser que obtivessem autorização expressa do pater familias. Apenas os bens castrenses (adquiridos nas guerra) ou quasi castrenses (ex: doações régias), podiam ser testados pelo filho, mesmo sem o consentimento paternal. Também os escravos, hereges, apóstatas, e religiosos professos estavam impedidos de testar, apesar destes últimos o poderem fazer antes dos votos solenes, dado que neste caso, este instrumento não podia ser anulado. No entanto ficavam impedidos de o alterar, uma vez que a partir desse momento assumiam o estado de mortis civis. Assim, os bens eram administrados pela ordem religiosa respetiva até à morte do testador, sendo depois entregues aos legatários. Igualmente, os surdos e os mudos de nascença viam negada a possibilidade de expressar as suas últimas vontades com enquadramento legal, excetuando-se aqueles que se faziam entender, ou que sabiam escrever. Por fim, os condenados à morte também eram impedidos de fazer os seus testamentos, ainda que a legislação permitisse que dispusessem da terça para causas pias; por isso os seus bens podiam ser utilizados para libertar cativos, casar órfãs ou dar esmolas aos hospitais, igrejas e mosteiros.

Importa dizer que existem diversas modalidades, enquadradas legalmente, a que os testadores poderiam recorrer para formalizar o seu testamento. $\mathrm{O}$ Título LXXX do Livro IV das Ordenações Filipinas distinguia três tipos de testamentos, o aberto, o cerrado e o nuncupativo, bem como os procedimentos a seguir para que cada um deles pudesse ser considerado "firme e valioso"

No que diz respeito ao testamento aberto, as Ordenações referem que qualquer pessoa podia testar, utilizando os serviços de um tabelião público. Normalmente, o testamento era redigido no livro de notas respetivo e implicava a presença de cinco testemunhas que tinham de obedecer aos seguintes requisitos: ter idade superior a 14 anos e ser varões livres ou tidos como livres, ou seja, do

\footnotetext{
${ }^{10}$ Ana Cristina Araújo, A morte em Lisboa, Lisboa, Editorial Notícias, 1997, p. 75.

${ }^{11}$ Ordenações Filipinas, Livro IV, Título 81, § 1.

${ }^{12}$ Ordenações Filipinas, Livro IV, Título 80.
} 
sexo masculino e não escravos. Importa explicar que o número de testemunhas que tinham de assistir à feitura do testamento, ou pelo menos à leitura das disposições aprovadas pelo testador, eram seis, já que às cinco anteriormente referidas se acrescentava o tabelião. No final, todas assinavam o documento, bem como o testador. A legislação previa que na eventualidade do testador não saber ou poder assinar, uma das testemunhas devia assinar por ele, indicando expressamente que o fazia a pedido deste.

O testamento cerrado, que também podia ser designado de místico, apresenta outras especificidades: como nos relembra Ana Cristina Araújo ${ }^{13}$, este tipo de testamento podia ser escrito pela mão do testador, sendo por isso hológrafo, ou por outra pessoa a pedido deste, e mantido em segredo. Na última opção, devia ser assinado pelo testador ou pela pessoa que o escreveu declarando essa situação, dado que, no caso de ser hológrafo, a veracidade da escritura estava garantida à partida, dispensando-se a assinatura como comprovativo ${ }^{14}$. Passado este momento, o testamento cerrado tinha de ser entregue ao tabelião pelo próprio testador, de modo a não comprometer a sua última vontade; devia ser em seguida lacrado e cosido perante seis testemunhas, que obedeciam aos mesmos critérios que explanámos em cima. Nesta fase, decorria um pequeno cerimonial que devia ser seguido escrupulosamente. O tabelião questionava o testador se a escritura que este lhe tinha entregue correspondia à sua última vontade, e, obtendo uma resposta afirmativa por parte deste, produzia o instrumento de aprovação que teria de ser assinado pelas testemunhas, para ser considerado válido. Desta forma, e apesar de validarem o testamento, as testemunhas mantinham total desconhecimento acerca do seu conteúdo. O incumprimento destas orientações implicava a perda do ofício para o tabelião e a nulidade do documento. Ainda no que se refere ao instrumento de aprovação, de modo a evitar falsificações, o tabelião era aconselhado a incluir o seu sinal em todas as páginas afim de garantir a autenticidade do instrumento. Depois de cosido e lacrado, o tabelião procurava encontrar um espaço vazio onde o pudesse autenticar, de modo a evitar falsificações. Isto é, testamento e aprovação deviam constituir uma peça única e indivisível.

Seguem-se os testamentos que "o testador poderá fazer ao tempo de sua morte por palavra"15, ou seja, os nuncupativos. Eram feitos à beira da morte, por se tratar de uma situação de emergência. Apesar de serem necessárias as mesmas seis testemunhas, neste caso era permitido às mulheres assumir esta

\footnotetext{
${ }^{13}$ Ana Cristina Araújo, A Morte em Lisboa, cit., p. 75.

${ }^{14}$ Ordenações Filipinas, Livro IV, Título 80, § 1.

${ }^{15}$ Ordenações Filipinas, Livro IV, Título 80, § 4.
} 
função, a qual lhes estava vedada nas duas categorias anteriormente referidas. Todavia, o processo para aferir a validade do documento era bastante complexo e exigia que todas as testemunhas fossem unânimes ao declarar a vontade do testador. Importa também assinalar que esta escritura só era válida se o testador falecesse; em caso de convalescença, devia fazer um novo testamento, desta vez escrito, e seguindo os trâmites acima referidos para os testamentos abertos ou cerrados.

No que se refere aos testamentos privilegiados, que tal como o próprio nome indica, diziam respeito a situações excecionais, podemos incluir nesta categoria os testamentos feitos por soldados em tempo de guerra e no campo da batalha (as exceções previstas não contemplavam a feitura dos testamentos em momentos de paz), em tempos de peste, ou os testamentos feitos por marítimos ou embarcados. No entanto, quando o testador sobrevivia o testamento deixava de ser válido, à semelhança do que acontecia com os testamentos nuncupativos.

Por fim, como refere Ana Cristina Araújo ${ }^{16}$, é importante mencionar o testamento de mão comum. Apesar de não possuir enquadramento jurídico nas Ordenações, era utilizado frequentemente. Tratava-se de um documento que reunia a vontade comum de duas ou mais pessoas (normalmente a vontade de marido e mulher, mas também de irmãos, ou pais e filhos). Tal como qualquer outro testamento, podia assumir a forma de cerrado, aberto ou nuncupativo.

\section{Cumprir as últimas vontades no Império: o provedor dos defuntos}

Isabel dos Guimarães Sá aponta duas razões que explicam a interferência das misericórdias na transferência de heranças do império para a metrópole. Por um lado, o facto de ser costume enraizado contemplar-se as misericórdias nos testamentos, continuando-se esta 'tradição' nos territórios da expansão; por outro lado, existia também uma razão afetiva, uma vez que os testadores desejavam fazer regressar os seus patrimónios às terras de origem, já que neste período o percurso migratório raramente envolvia o regresso à terra natal ${ }^{17}$.

Assim, é relevante refletir acerca dos motivos que podem explicar o não retorno. Para além das questões logísticas da viagem, podemos distinguir outros fatores que explicam esta situação. Desde logo, devido ao facto de a maioria da população que se deslocara para estes territórios não conseguir constituir fortuna, ou porque, quando criada, era mais fácil usufruir dela no novo ambiente

\footnotetext{
${ }^{16}$ Ana Cristina Araújo, A Morte em Lisboa, cit., p. 77.

${ }^{17}$ Isabel dos Guimarães Sá, As Misericórdias Portuguesas de D. Manuel a Pombal, Lisboa, Livros Horizonte, 2001, p. 52.
} 
do que voltar ao reino. Este fenómeno é particularmente incisivo nos soldados, que assumiram uma presença significativa no Oriente ${ }^{18}$. O relato de um deles materializa o que referimos anteriormente: "ser soldado tão longe da pátria, comer, vestir e calçar à sua custa, alugar casa de sua bolsa, comprar armas com o seu dinheiro, e estar prestes para se embarcar de armada, sem mais que uma só paga cada ano e às vezes nenhuma - parece coisa impossível a quem não for comendador de Malta". ${ }^{19}$ Uma última explicação está relacionada com o facto de, contrariamente ao que acontecia no Império Espanhol, no caso português, os homens partiam sem as esposas, generalizando-se as uniões informais e até encorajando-se os casamentos mistos (como fez Albuquerque em Goa), o que fazia com que diminuísse a força do chamamento familiar.

A transmissão de bens a uma escala intercontinental implicou a atuação de várias figuras institucionais e de esferas que se interpenetravam. Neste ponto, talvez seja pertinente referir que existem algumas dimensões dentro desta temática ainda pouco estudadas, como a articulação entre os oficiais régios e misericórdias. Como vimos, os testamentos eram feitos nos notários ou tabeliães, eles próprios nomeados pelo rei, requerendo a intervenção de testemunhas. Embora um ato de natureza privada em si, o testamento, ao necessitar da validação do notário, apelava de forma imediata a uma instituição pública. Desta interpenetração entre a esfera privada e a pública decorria a necessidade do testamento cerrado, que constituía a forma mais sigilosa, e portanto menos pública, de elaborar o testamento.

Se elaborar um testamento já constituía um ato público em si, fazê-lo cumprir era praticamente impossível sem a interferência de outras instituições, sobretudo quando se tratava de cumprir a vontade dos defuntos, e salvaguardar os interesses dos herdeiros. Nesse campo, temos a considerar os provedores de defuntos da coroa, os juízes dos órfãos, no caso de existirem herdeiros menores, e por vezes, os ouvidores.

Posto isto, é fundamental centrar a nossa atenção em primeiro lugar nos provedores dos defuntos. Como nos diz António Manuel Hespanha, eram funcionários da administração periférica, bastante especializados, que acumulavam duas grandes áreas de competência. Por um lado, tutelavam os interesses dos titulares que não estavam em condições de administrar bens, nos quais podemos incluir os defuntos, os ausentes, os órfãos, e os cativos, mas também pessoas coletivas como hospitais ou capelas. Por outro, lidavam com assuntos de finanças, tendo de verificar livros, cuidar de arrendamentos

\footnotetext{
${ }^{18}$ Inês Amorim, Misericórdia de Aveiro ..., cit., p. 121.

${ }^{19}$ Citado por Inês Amorim, Misericórdia de Aveiro ..., cit., p. 121.
} 
reais, tomar contas de almoxarifes e recebedores, entre outros. Relativamente aos ausentes, era da responsabilidade do provedor administrar os seus bens e entregá-los a quem os reclamasse, dando apelação e agravo para a justiça ordinária ${ }^{20}$.

Apesar de alguns autores defenderem que a Provedoria dos Defuntos e Ausentes foi regulada em $1588^{21}$, o primeiro regimento de que dispomos data de 10 de Dezembro de $1613^{22}$. Este último contém as disposições específicas para o funcionamento deste cargo no Brasil, São Tomé, Cabo Verde, Açores e outras partes ultramarinas, pelo que necessita de uma análise detalhada. Desde logo, dá-nos a indicação de que nestes lugares as provedorias deviam ser compostas por um provedor, acompanhado do respetivo escrivão, e do tesoureiro. Por seu turno, na capital do reino, existia um tesoureiro-geral dos defuntos que assumia a responsabilidade de gerir e fiscalizar as contas das provedorias de todos os territórios sob administração portuguesa, estando sob tutela da Mesa de Consciência e Ordens.

Como já tivemos oportunidade de referir, os provedores dos defuntos estavam incumbidos de inspecionar e arrecadar os bens móveis ou de raiz de todas as pessoas que falecessem além-mar sem deixarem herdeiros exclusivamente na terra onde faleciam. Todavia, o próprio regimento é claro ao referir que esta disposição não teria lugar se os defuntos deixassem em testamento uma ou mais pessoas encarregues de administrar os seus bens. Porém, estes testamenteiros teriam de se encontrar suficientemente próximo para poderem ser notificados em 30 dias de que deviam proceder à execução do testamento. No entanto, no caso de os defuntos serem responsáveis pela administração de alguma herança pertencente a outra pessoa aquando da sua morte, os provedores tinham a responsabilidade de supervisionar a atuação desse testamenteiro.

Outra das responsabilidades deste oficial régio relaciona-se com a arrecadação da fazenda das pessoas que fizessem a viagem para o território das suas provedorias e falecessem no mar durante a mesma, mas também em qualquer porto onde o navio atracasse. Consequentemente, seria este provedor dos defuntos a ser contactado pelos herdeiros, ou por outros provedores dos

${ }^{20}$ António Manuel Hespanha, As Vésperas do Leviathan - Instituições e Poder Politico em Portugal no Século XVII, Lisboa, Edições Almedia, 2007, p. 202.

${ }^{21}$ Angélica Rici Camargo, Provedor/Provedoria dos Defuntos e Ausentes, (2003) (http:// linux.an.gov.br/mapa/?p=4421, consultado em 2015-10-03); Inês Amorim, Misericórdia de Aveiro ..., cit., sugere o século XVI.

${ }^{22}$ Regimento dos Provedores e mais Oficiais das Fazendas dos Defuntos e Ausentes do Ultramar, e das Ilhas Adjacentes, 10 de Dezembro de 1613 (http://www.iuslusitaniae.fcsh.unl. pt/verlivro.php?id_parte=130\&id_obra=81\&pagina=169, consultado em 2015.06.27). 
defuntos, e ainda outros eventuais interessados que pretendessem tomar entrega dos bens entretanto arrecadados.

O provedor era obrigado pelo regimento a seguir um conjunto de procedimentos na arrecadação dos bens. Sempre que tivesse conhecimento de que a sua atuação era necessária, devia deslocar-se com o tesoureiro e escrivão à casa do defunto para proceder de imediato à inventariação de todos os seus bens e papéis. Era este o primeiro passo; nesta fase, devia também interrogar as pessoas que ficaram na casa onde ocorreu o óbito, bem como quaisquer outros sujeitos que considerasse importante ouvir. Neste inventário proceder-se-ia à identificação do defunto, anotando a sua naturalidade, estado, bem como as circunstâncias da sua morte e, caso existissem, proceder ao treslado de escrituras, nomeadamente testamentos, e conhecimentos de dívidas. O provedor tinha também o poder de arrecadar os bens dos defuntos que estivessem em poder de outras pessoas, bem como as suas dívidas passivas, tendo por isso, neste campo, a mesma jurisdição dos Almoxarifes Executores e Recebedores da Fazenda.

Morrer durante uma viagem constituía uma situação excecional à face da lei. Como vimos, aquando da análise dos testamentos privilegiados, esta situação estava acautelada através do testamento marítimo. Também a atuação deste oficial régio apresentava contornos particulares nesta matéria. Assim, na eventualidade de alguém falecer em viagem, mandar-se-ia fazer pelo escrivão do Capitão, Mestre ou Piloto do navio um inventário de toda a fazenda do falecido, tendo este documento de ser assinado por todas as pessoas a bordo do navio. Chegados ao destino (mesmo que a viagem implicasse uma escala num outro porto, o assunto teria de ser tratado pelo provedor com jurisdição relativa ao destino final), o responsável do navio entregava o inventário na provedoria, devendo ser reembolsado pelas despesas que pudessem ter entretanto ocorrido.

Outra dimensão explicada no regimento, em capítulo próprio ${ }^{23}$, prende-se com a venda ou arrendamento dos bens, o pagamento das despesas do funeral, dos legados e das dívidas dos defuntos. Competia ao provedor dos defuntos leiloar os móveis e vendê-los ao maior lançador, em presença do escrivão e tesoureiro. Em contraste, a venda dos bens de raiz era interdita caso os herdeiros do falecido não tivessem conhecimento dos mesmos, limitando-se a provedoria a arrendá-los interinamente em leilão. A participação na hasta pública estava vedada aos funcionários da provedoria, bem como a pessoas entrepostas por

${ }^{23}$ Regimento dos Provedores e mais Oficiais das Fazendas dos Defuntos e Ausentes do Ultramar, e das Ilhas Adjacentes, Capítulo V, 10 de Dezembro de 1613 (http://www.iuslusitaniae. fcsh.unl.pt/verlivro.php?id_parte=130\&id_obra=81\&pagina=169, consultado em 2015.06.27). 
estes. O incumprimento desta norma e/ou o usufruto dos bens dos defuntos implicava a perda do ofício por parte dos oficiais régios.

No que diz respeito à realização das cerimónias fúnebres, o regimento previa diferentes cenários. Na existência de um testamento solene, se nele estivessem incluídos legados, sufrágios, funeral, bem como outras obras pias por alma do testador, o provedor teria de os mandar satisfazer através da fazenda do defunto. Porém, caso o falecido morresse abintestado, a despesa do enterro, das exéquias e dos sufrágios não poderia exceder os 10 mil reis $^{24}$. Os defuntos deveriam ter um funeral de acordo com a sua fazenda, determinado pelo provedor e pelo bispo. Nesta época, a morte assumia grande importância no imaginário coletivo, que a legislação também exprimia, acautelando a realização de um cerimonial mínimo para quem não deixasse bens suficientes para o pagar, limitado a uma missa com o responso respetivo.

Outra das dimensões abrangidas na legislação prende-se com a arrecadação do dinheiro e a sua remessa para o reino. Uma das primeiras preocupações constituía em assegurar a segurança dos bens. Dinheiro e valores deveriam ser encerrados num cofre de três chaves, uma para o provedor, outra para o tesoureiro e a última para o escrivão. Consequentemente, o cofre só poderia ser aberto na presença dos três intervenientes, reduzindo-se a possibilidade de um furto interno. Para além desta medida de segurança, o tesoureiro teria de registar no livro de receitas as quantias colocadas no cofre, sempre que tal ocorresse. Naturalmente, ninguém poderia apropriar-se de alguma coisa que fosse pertença dos defuntos e ausentes.

O regimento sugeria que o dinheiro fosse remetido para Lisboa recorrendo a letras seguras a pagar no Tesoureiro Geral dos Defuntos, num prazo de 60 dias a contar do momento em que se finalizasse a arrecadação dos bens. A acompanhar as letras devia ser enviada a documentação relativa a cada legado, nos quais constava o nome, a morada, ocupação e estado do defunto, bem como o treslado dos inventários e testamentos. Estes processos seguiam em duplicado, tendo como destinatários a Mesa da Consciência e Ordens, que reenviava um duplicado para o Tesoureiro Geral dos Defuntos. É relevante salientar que a legislação promovia o envio do dinheiro por letras "pois é este o meio mais seguro e breve de se enviarem ao Reino os ditos dinheiros" ${ }^{25}$. Todavia, nem

${ }^{24}$ Regimento dos Provedores e mais Oficiais das Fazendas dos Defuntos e Ausentes do Ultramar, e das Ilhas Adjacentes, Capítulo V, §2, 10 de Dezembro de 1613.(http://www. iuslusitaniae.fcsh.unl.pt/verlivro.php?id_parte=130\&id_obra=81\&pagina=169, consultado em 2015.06.27).

${ }^{25}$ Regimento dos Provedores e mais Oficiais das Fazendas dos Defuntos e Ausentes do Ultramar, e das Ilhas Adjacentes, Capítulo IX, §3, 10 de Dezembro de 1613.(http://www. 
sempre se utilizava esta modalidade para se proceder à entrega das heranças, já que, por vezes, a tarefa de conseguir letras seguras se revelava hercúlea. Perante esta situação, experimentavam-se outras soluções. Por exemplo, em carta régia de 14 de Setembro de 1611, determina-se que o produto da fazenda dos defuntos no Brasil fosse remetido em ouro quando não existissem letras seguras, à semelhança no que acontecia na $\mathrm{Mina}^{26}$.

A preocupação com a veracidade das informações prestadas pelos oficiais era tão manifesta, que a cada seis meses, os provedores recebiam dos tesoureiros um livro rubricado e numerado, onde estavam inscritas as várias adições da entrada do dinheiro, bem como a identificação do defunto a que correspondiam. Por outro lado, também eram registadas as despesas efetuadas. Se se vislumbrassem sinais de negligência, os oficiais podiam ser alvo de suspensão; mesmo depois de terminado o seu mandato os funcionários estavam sujeitos a sanções. Por exemplo, os tesoureiros eram obrigados a apresentar as contas à Mesa da Consciência, no final do seu mandato, tendo um prazo definido para o fazer, que variava consoante a parte do Império onde se encontravam.

Finalmente, a legislação enfatizava que nenhuma autoridade podia tomar o dinheiro dos defuntos. Governadores, capitães, bispos ou quaisquer outras autoridades estavam impedidos de o utilizar, mesmo possuindo uma ordem assinada pelo rei. Uma Carta Régia, datada de 16 de Setembro de 1608, vincava esta proibição: todos estavam proibidos de tirar "dinheiro dos defuntos e ausentes fosse em que ocasião fosse, por mais necessária que seja, mesmo que para isso tenham ordem assinada pelo rei, sob pena de o pagarem da sua fazenda" 27 .

Estas missivas podem ter constituído uma reação da Coroa perante repetidas apropriações das fazendas dos defuntos. Efetivamente, algumas referências permitem-nos aventar esta hipótese. Outra epístola emanada a 20 de Julho de 1604 relata-nos que Manoel Roriz tomou dinheiro da fazenda dos defuntos da capitania de Pernambuco para construir uma fortaleza em Rio Grande. Para resolver o problema, o rei determinou que Roriz teria dois meses para repor o dinheiro a partir do dia em que recebesse a sua resposta ${ }^{28}$. No entanto, passados

iuslusitaniae.fcsh.unl.pt/verlivro.php?id_parte=130\&id_obra=81\&pagina=176, consultado em 2015.06.27).

${ }^{26}$ Carta Régia de 14 de Setembro de 1611.(http://www.iuslusitaniae.fcsh.unl.pt/verlivro. php?id_parte=94\&id_obra=63\&pagina $=982$, consultado em 2015.09.24).

${ }_{27}$ Carta Régia, 16 de Setembro de 1608, (http://www.iuslusitaniae.fcsh.unl.pt/verlivro. php?id_parte=94\&id_obra $=63 \&$ pagina $=742$, consultado em 2015.09.25).

${ }^{28}$ Carta Régia, 20 de Julho de 1604 (http://www.iuslusitaniae.fcsh.unl.pt/verlivro.php?id parte $=94 \&$ id_obra $=63 \&$ pagina $=462$, consultado em 2015.09.25). 
14 meses, a 20 de Setembro de 1605, foram-lhe concedidos mais dois meses para liquidar a dívida ${ }^{29}$. Finalmente, a 31 de Julho de 1606, uma nova missiva régia ordenava-lhe que não se protelasse mais o pagamento, uma vez que o dinheiro pertencia a pessoas pobres, viúvas e órfãos. Contudo, caso este não fosse considerado culpado, e "como os herdeiros viviam uma situação complicada, devia pagar-se a quantia utilizando a fazenda do rei" ${ }^{30}$.

Estes abusos parecem recorrentes como sinaliza Wellington Costa ${ }^{31}$. Nas cartas que enviavam ao rei, muitas autoridades denunciavam os excessos cometidos por outros oficiais. A 27 de Maio de 1698, Artur de Sá e Meneses, Governador da Capitania do Rio de Janeiro, acusou a má arrecadação da fazenda dos defuntos da Vila de Santos, já que todo o dinheiro se extraviara. Outros casos semelhantes ocorreram na mesma capitania em 1714 e 1750, verificando-se também a existência de anomalias análogas noutras capitanias como Pernambuco, Ceará ou Baía.

\section{O papel das misericórdias na transmissão de heranças}

Embora a provedoria dos defuntos devesse atuar, como dissemos, em territórios como o Brasil, São Tomé, Cabo Verde ou Açores, no Oriente a situação era bem diferente uma vez que a Coroa concedeu competências formais às misericórdias para atuarem nesta matéria, embora em conexão com as provedorias dos defuntos e com as próprias ouvidorias, nos casos em que a lei o requeresse (os ouvidores, por exemplo, validavam últimas vontades e codicilos que não tivessem sido elaborados perante notário).

Como e a partir de quando é que as misericórdias asiáticas passaram a desempenhar um papel ativo na transferência de propriedade entre a metrópole e os territórios do império? É provável que a situação de facto fosse anterior à feitura da lei, uma vez que a existência de uma rede de misericórdias permitia um fluxo regular de correspondência. Em todo o caso, o Alvará de 26 de Maio de 1590 determinava que as fazendas e bens dos defuntos que tivessem herdeiros na metrópole, e falecessem nas Fortalezas de Moçambique, Ormuz, Diu, Damão,

${ }^{29}$ Carta Régia, 20 de Setembro de 1605 (http://www.iuslusitaniae.fcsh.unl.pt/verlivro. php?id_parte=94\&id_obra=63\&pagina $=429$, consultado em 2015.09.25).

${ }^{30}$ Carta Régia, 31 de Julho de 1606 (http://www.iuslusitaniae.fcsh.unl.pt/verlivro.php?id parte $=94 \&$ id_obra $=63 \&$ pagina $=648$, consultado em 2015.09.25).

${ }^{31}$ Wellington Júnio Guimarães da Costa, Das Desordens na Provedoria de Defuntos e Ausentes, Capelas e Resíduos na América Portuguesa, (2015) (http://www.snh2015.anpuh. org/resources/anais/39/1434426149_ARQUIVO_TextoANPUHWellington.pdf., consultado em 2015.12.02). 
Baçaim, Chaúl, Goa e outras partes do Estado da Índia deviam ser entregues às misericórdias locais, que por sua vez as remeteriam à Misericórdia de Goa, de onde deviam seguir para Lisboa recorrendo a letras de modo a se proceder-se à entrega dos bens aos seus legítimos possuidores ${ }^{32}$. Isabel dos Guimarães Sá pode ajudar-nos a entender todo o processo:

"A lei prescrevia regras rigorosas sobre o inventário e partilha de bens de defuntos que, a serem cumpridas, garantiam a transmissão de bens aos herdeiros. Á morte do individuo, os provedores dos defuntos deviam fazer um inventário dos bens, que eram em seguida depositados nas Misericórdias do Estado. Estes eram convertidos em moedas e depositados no cofre dos depósitos e deviam ser transportados para a Misericórdia de Goa que tinha como missão fazê-los chegar aos herdeiros ${ }^{33}$ ".

Esta prerrogativa das misericórdias do Estado da Índia foi reafirmada através de uma carta de 12 de Fevereiro de 1615, onde se dava conta de que as misericórdias deviam continuar a observar o mesmo procedimento na arrecadação e entrega de fazenda dos defuntos e ausentes. Porém, deviam emendar as falhas, seguindo o exemplo da Santa Casa da Misericórdia de Goa, pois os seus procedimentos na matéria eram tidos como exemplares. Assim, todas as misericórdias ficavam obrigadas a possuir um cofre com três chaves, distribuídas pelo provedor, escrivão da mesa e tesoureiro, um procedimento usual em qualquer instituição para guardar valores em arcas blindadas, como já tivemos oportunidade de destacar acima ${ }^{34}$.

Mais tarde, a Provisão de 26 de Maio de 1649, proibiu os religiosos particulares de se tornarem testamenteiros, ao mesmo tempo que se passou a exigir que os testamenteiros leigos cumprissem as disposições testamentárias do defunto em quatro anos. Se as últimas vontades não fossem cumpridas neste prazo, as misericórdias podiam administrá-las como estava definido no Alvará de $1590^{35}$. Este enquadramento legal constituiu uma das razões principais que potenciaram o desenvolvimento formal de uma rede de comunicação entre as misericórdias que unia diferentes partes do Império Português. Como nos diz Magalhães:

32 Alvará de 26 de Maio de 1590 (http://www.iuslusitaniae.fcsh.unl.pt/verlivro.php?id_ parte $=100 \&$ id_obra $=63 \&$ pagina $=133$, consultado em 2015.10.27).

${ }^{33}$ Isabel dos Guimarães Sá, Quando o rico se faz pobre ..., cit., p. 243.

${ }^{34}$ Carta Régia, 12 de Fevereiro de 1615 (http://www.iuslusitaniae.fcsh.unl.pt/verlivro. php?id_parte=95\&id_obra=63\&pagina=366, consultado em 2015.10.27).

${ }_{35}$ Provisão de 26 de Maio de 1649, (http://www.iuslusitaniae.fcsh.unl.pt/verlivro.php?id parte $=100 \&$ id_obra $=63 \&$ pagina $=133$ consultado em 2015.10.27). 
"A variedade da documentação disponível e a sua recorrência desde a última década do século XVI até ao final do século XVIII, permitem-nos estabelecer um quadro muito vivo da enorme rede de contactos estabelecida com os pontos mais distantes do território governado pela Coroa de Portugal. Encontrámos uma teia urdida em múltiplas direções e com variados pontos de intersecção ${ }^{36}$ ".

A distância que as heranças tinham de percorrer, associada aos interesses em possível conflito e às muitas pessoas envolvidas, arrastavam os processos durante muito tempo, podendo inclusivamente conduzir à não arrecadação dos legados. Disto dá nota uma carta escrita em Guimarães, a 6 de Março de 1646, com destino a Goa, referente ao legado de Lucas Leitão Coelho, que permanecia há mais de 20 anos no depósito da sua misericórdia ${ }^{37}$. Como já referimos, esta demora no pagamento pode ser explicada pelo facto de muitas vezes o dinheiro dos ausentes ser utilizado para outras finalidades. Quando o Estado da Índia, por exemplo, se via aflito, recorria a este depósito para fazer face a necessidades consideradas prementes, como por exemplo aquando das investidas holandesas ${ }^{38}$. Nas cartas onde a irmandade de Goa justificava a demora no pagamento, alguns trechos culpavam o rei pela utilização desses fundos; por exemplo, a 6 de Março de 1646 diz-se que os bens dos defuntos foram tomados por serviço de Sua Majestade ${ }^{39}$, repetindo-se a mesma justificação em 1649 e $1651^{40}$. Os ataques perpetrados pelos holandeses criaram um clima de grande instabilidade e emergência financeira, que implicou tomar posse dos capitais de várias instituições, dos privados e das próprias câmaras ${ }^{41}$. Mas mesmo em períodos anteriores encontramos várias referências à utilização do dinheiro dos defuntos por parte das instituições coloniais. Para além do auxílio à Coroa em momentos de emergência bélica, temos também notícia de que as próprias instituições locais podiam lançar mão das heranças. Por exemplo, através da carta de 13 de Março de 1653, ficamos a saber que o dinheiro de Francisco de Novais, falecido na China no ano de 1628, fora utilizado nas obras da Sé de $\mathrm{Goa}^{42}$. Outras investigações também encontraram referências ao uso do dinheiro em obras na sé de Goa, adiantando que mesmo quando as obras não

\footnotetext{
${ }^{36}$ António Magalhães, Práticas de caridade na misericórdia de Viana da Foz do Lima (Séculos XVI - XVIII), tese de doutoramento, Braga, Universidade do Minho, 2009, p. 108.

${ }^{37}$ Arquivo Histórico da Santa Casa da Misericórdia de Guimarães (Doravante AHSCMG), Livro 189, fl. 6v.

${ }^{38}$ Isabel dos Guimarães Sá, Quando o rico ..., cit., p.253.

${ }^{39}$ AHSCMG, Livro 189, fl. 3.

${ }^{40}$ AHSCMG, Livro 189, fl. 3.

${ }^{41}$ Isabel dos Guimarães Sá, Quando o rico ..., cit., p. 241.

${ }^{42}$ AHSCMG, Livro 189, fl. 8.
} 
avançavam, os tesoureiros da Sé retiravam dinheiro a herdeiros conhecidos. Esta menção a herdeiros conhecidos relaciona-se com o facto de poderem existir defuntos abintestados, ou seja, que não tinham testamento. Nesta situação aumentava-se exponencialmente o tempo de espera até se dispor da herança, uma vez que era necessário confirmar a veracidade dos herdeiros ${ }^{43}$. Para que o fizessem, era necessário fazer chegar as cartas à metrópole noticiando as heranças, e muitas vezes as próprias misericórdias metropolitanas trataram de indagar a existência de herdeiros. Por exemplo, este papel foi assumido pela Misericórdia de Guimarães quando teve de encontrar os herdeiros de António Leite de Azevedo, que uma carta enviada pela Misericórdia de Cochim no dia 5 de Dezembro de 1653 dava como tendo falecido nessa cidade. Visto que a pessoa nomeada no testamento (onde não está definido os laços familiares que os unia), Maria, filha natural de Pedro Machado, morador na Quinta do Sobrado, em Santa Senhorinha, já tinha falecido, a Misericórdia chegou à filha desta, Catarina Macedo de Machado, que vivia na freguesia de Cavez, fronteiriça a Santa Senhorinha ${ }^{44}$. Todo este processo aumentava o tempo de espera e tornava o dinheiro mais apetecível visto que passado um determinado número de anos ${ }^{45}$, os herdeiros deixavam de poder reclamar as suas heranças. Catarina de Novais, herdeira do defunto Francisco de Novais, viu a Misericórdia de Goa dizer em 31 de Março de 1651 que o dinheiro da sua herança fora utilizado nas obras da Sé de Goa. Em sua defesa, a sua congénere de Guimarães explicou que tinha diligenciado dentro do prazo, pelo que não poderia deixar de ter direito a cobrar o legado ${ }^{46}$.

As fontes documentam duas formas comuns de fazer chegar o dito dinheiro à metrópole: por uma pessoa de certa posição social, ou pelo meio de letras. Como já referimos a propósito da provedoria dos defuntos, este último meio de transferência era por vezes difícil de conseguir. A Misericórdia de Guimarães tentou outras soluções quando se deparou com o problema. Como podia ser difícil encontrar uma pessoa disponível para trazer estas quantias e dado que poderiam surgir dificuldades no pagamento das letras ${ }^{47}$, a Misericórdia

${ }^{43}$ Inês Amorim, Misericórdia de Aveiro ..., cit., p.129.

${ }^{44}$ AHSCMG, Livro 189, fl. 15v.

${ }^{45}$ Não conseguimos precisar o número de anos. Todavia, como se trata de uma questão importante tentaremos dar resposta num futuro próximo.

${ }^{46}$ AHSCMG, Livro 189, fl. 8.

${ }^{47}$ Veja-se o caso de Ponte de Lima, que perante uma experiência negativa com um mercador da ribeira do Minho, não queria que as letras viessem por mercadores dessa região. Marta Lobo Araújo, Dar aos pobres e emprestar a Deus: As Misericórdias de Vila Viçosa e de Ponte de Lima (séculos XVI-XVIII), tese de doutoramento, Braga, Universidade do Minho, 2000, p. 434. 
de Guimarães propôs, num caso muito específico, uma forma de pagamento diferente destas duas. O caso passou-se com Gonçalo da Fonseca, que solicitou em 26 de Janeiro de 1653 à Misericórdia de Guimarães que administrasse uma capela. Assim, a irmandade sugeriu que o dito Gonçalo Pinto da Fonseca fosse levantar os rendimentos da mesma à Misericórdia de Goa. Para proceder a este pagamento, a Santa Casa goesa deveria utilizar o dinheiro dos legados que estavam a ser cobrados pela Misericórdia de Guimarães. Por sua vez, os herdeiros em Guimarães recebiam o legado através dos rendimentos da capela, evitando-se uma viagem entre a Índia e Guimarães, com os perigos subsequentes. Na verdade, os naufrágios e a pirataria levavam a que se dessem ordens específicas para que as heranças fossem repartidas entre as várias naus que se lançavam ao oceano. Talvez seja pertinente transcrever exatamente o que nos diz a documentação enviada a Goa:

"E que lhe fiquem na mão em pago do que daqui em diante devemos cobrar dos rendimentos da sua capela, utilizaremos a mesma quantia para pagarmos aos ditos herdeiros de António Leite de Azevedo. E por este meio se evita a jornada de ida e vinda ${ }^{48}$.

Para além de todas estas contrariedades, alguns autores defendem que estas instituições recorriam a estratégias ilícitas de modo a aumentar o tempo de permanência dos legados no depósito com o intuito de aumentarem os juros, sobretudo invocando o extravio de documentos. Todos estes fatores levaram a que emergisse um clima de suspeita sobre as misericórdias, pois os tempos de espera se tornavam anormalmente longos ${ }^{49}$. A Misericórdia de Guimarães, por exemplo, repetia exaustivamente a necessidade de receber as heranças, quer por parte dos herdeiros, quer as esmolas e legados que os defuntos deixavam à própria confraria, sem que a pressão exercida conseguisse acelerar o processo ${ }^{50}$. Efetivamente, ainda em 1654, e passados 26 anos da morte de Francisco Novais Gago, a irmandade de Guimarães solicitava à sua congénere de Goa que lhe enviasse os bens que este deixara a Catarina Novais ${ }^{51}$.

A documentação que consultámos no Arquivo da Santa Casa da Misericórdia de Guimarães, bem como na documentação referente à Misericórdia de Caminha

${ }^{48}$ Arquivo Histórico da Santa Casa da Misericórdia de Guimarães (Doravante AHSCMG) L $^{\circ} 189$, fl. 11v.

${ }^{49}$ Marta Lobo Araújo, Dar aos pobres ..., cit., p. 432.

${ }^{50}$ AHSCMG, Livro 189, fl. 18.

${ }^{51}$ AHSCMG, Livro 189, fl. 10v. 
e de Viana do Castelo ${ }^{52}$ confirmam a tendência verificada noutros estudos ${ }^{53}$. Conseguimos encontrar cartas trocadas com Goa, Macau, Cochim, Mombaça, Moçambique, Angola, Funchal, Bahia e Lisboa ${ }^{54}$, correspondência que comprova esta dimensão, surgindo algumas misericórdias que se transformam em verdadeiras plataformas de distribuição das cartas, como é o caso das supracitadas Lisboa e Goa. Podemos comprová-lo, por exemplo, através da carta escrita pelos irmãos da Misericórdia de Guimarães a Goa, datada de 8 de Março de 1669:

"Também remetemos as mais cartas que vinham para pessoas naturais desta vila, que a Misericórdia de Lisboa nos remeteu que tinham vindo dessa Santa Casa" $" 55$.

Tudo isto nos leva a crer que existia um sistema bem oleado que possibilitava a comunicação rotineira entre as diversas áreas administradas pela Coroa Portuguesa, fazendo com que estas confrarias contribuíssem para uma maior articulação entre a metrópole e os territórios de além-mar, incluindo também a troca de missivas com particulares. Não só entre as misericórdias do Oriente e a metrópole (que como vimos tinham funções oficiais como provedoras de defuntos), mas também entre todas as misericórdias entre si, conforme se comprova pelo facto de encontrarmos cartas provenientes de todos os territórios da expansão portuguesa, e mesmo ibérica, nos arquivos destas confrarias. Estas irmandades solicitavam informações e serviços umas às outras, muito embora a maioria das cartas se relacionasse com a transmissão de heranças e cumprimento dos legados. De resto, é necessário destacar que o processo de certificação de herdeiros requeria a intervenção de muitas outras instituições públicas, uma vez que eram necessários registos paroquiais e mesmo certidões de escrituras notariais ${ }^{56}$, cujos documentos era suposto estarem na posse das misericórdias.

Como vimos, a Misericórdia de Goa ocupava uma posição fundamental no que respeita às misericórdias do Estado da Índia: “As misericórdias não agiam de forma autónoma relativamente às heranças dos portugueses, sendo obrigadas

${ }^{52}$ Arquivo Distrital de Viana do Castelo (Doravante ADVC), Misericórdia de Viana do Castelo; ADVC, Misericórdia de Caminha.

${ }^{53}$ Inês Amorim, Misericórdia de Aveiro ..., cit., Isabel dos Guimarães Sá, Quando o rico se faz pobre ..., cit.; Marta Lobo Araújo, Dar aos pobres..., cit.; Américo Costa, Poder e conflito : a Santa Casa da Misericórdia de Guimarães : (1650-1800), Braga, Universidade do Minho, 1997; António Magalhães, Práticas de caridade ..., cit.

${ }^{54}$ AHSCMG, Livro 189.

${ }^{55}$ AHSCMG, Livro 189, fl. 38v.

${ }^{56}$ Inês Amorim, Misericórdia de Aveiro ..., cit., p. 129. 
a remeter os espólios respetivos à Misericórdia de Goa ${ }^{57}$ ". Goa partilhava inicialmente esta centralidade com a Misericórdia de Cochim, embora a primeira tivesse adquirido exclusividade nessa matéria com o passar do tempo ${ }^{58}$. É relevante referir que esta posição dominante por parte de Goa, para além de poder ser comprovada na transferência das heranças, é também verificável noutros domínios. Assim, por exemplo, em 1610, num contexto de ameaças exteriores, coube à confraria de Goa auxiliar as Misericórdias de Cananor e Ceilão; por outro lado, e dada a progressiva perda dos territórios no Oriente, foi a Santa Casa goesa que liquidou os remanescentes das misericórdias entretanto extintas. Desta supremacia da confraria de Goa, aparentemente, apenas se excluiu a Misericórdia de Macau. Curiosamente, esta última irmandade assumiu uma posição de destaque relativamente às suas congéneres na região, como por exemplo as misericórdias do Japão ${ }^{59}$.

Desta forma, podemos afirmar que Goa se transformou numa plataforma onde chegavam e de onde partiam informações das restantes misericórdias do Estado da Índia. Existiam inclusivamente regras especificas que deviam ser seguidas na transmissão de legados. Num primeiro momento, os bens eram inventariados na misericórdia onde o indivíduo falecia, procedendo-se igualmente ao apuramento dos créditos ou débitos, bem como à sua resolução, sendo o saldo enviado para a confraria de Goa $^{60}$. Era já sob alçada desta última que se iniciava o processo de procura dos herdeiros, contactando as misericórdias de onde os defuntos eram naturais, através da misericórdia de Lisboa. Aliás, a centralidade que Goa ocupava no Estado da Índia tinha algum paralelismo no lugar ocupado pela Misericórdia de Lisboa na metrópole. Esta última desempenhava esse papel em consonância com o seu lugar de capital do Reino, sendo a sua misericórdia a mais antiga e de maior envergadura, enquanto Goa era capital do Estado da Índia, onde residia o vice-rei.

\section{Conclusões}

Fizemos aqui uma primeira abordagem ao estudo da provedoria dos defuntos. Todavia, a partir desta pesquisa já conseguimos encontrar algumas pistas que nos permitem compreender melhor a atuação dos oficiais respetivos.

${ }^{57}$ Isabel dos Guimarães Sá, Quando o rico se faz pobre ..., cit., p. 261.

${ }^{58}$ Isabel dos Guimarães Sá, As Misericórdias Portuguesas ..., cit., p.52.

${ }^{59}$ Isabel dos Guimarães Sá, Quando o rico..., cit., p. 270.

${ }^{60}$ José Ferreira Martins, História da Misericórdia de Goa, vol. II, Goa, Imprensa Nacional, 1912 , p. 427. 
Primeiramente é imperioso destacar o complexo sistema montado para se proceder à cobrança das heranças, de forma a cumprir a última vontade dos defuntos. Como vimos, a sua provedoria era composta pelo provedor, pelo escrivão e pelo tesoureiro, que desempenhavam funções especializadas e se correspondiam com a Mesa da Consciência e Ordens, bem como com o Tesoureiro Geral dos Defuntos. Mas é necessário também chamar a atenção para uma diferença fundamental: enquanto no Oriente Goa ou Cochim podiam desempenhar um papel central, servindo de plataformas de envio de correspondência e liderando os processos de transferência de bens, no Brasil não parece ter havido nenhuma misericórdia que assumisse esse papel de coordenação. De facto, é importante salientar que aparentemente o sistema que vigora no Estado da Índia não é reaplicado no eixo atlântico, onde as misericórdias não assumem tanta relevância.

Dada a morosidade das comunicações (as viagens de ida e retorno de Portugal para a Ásia podiam demorar um ano ou mais) e o processo complexo de certificação de herdeiros, o tempo necessário para terminar os procedimentos legais aumentava exponencialmente. Apesar de o enquadramento legal tentar evitar a fuga do dinheiro e o desvio de bens, na verdade estes poderiam facilmente ocorrer. Assim, os herdeiros corriam o risco de receber uma parte muito reduzida da herança que lhes tinha sido inicialmente destinada, pois, como tivemos oportunidade de verificar, existiam muitos interesses e pessoas envolvidas.

A legislação sobre a provedoria dos defuntos não sofreu alterações significativas ao longo do tempo, fazendo que fossem as Ordenações Filipinas a nortear o direito de família e a transmissão de bens durante muitos anos. Todavia, a influência da Igreja nos testamentos foi muito intensa, tendo sido hegemónica neste campo até ao reinado de D. José ${ }^{61}$. A partir de então, enfrentou as imposições e interdições resultantes das medidas de Pombal. Mais tarde, a lei de 22 de setembro de 1828, que extinguiu a Mesa do Desembargo do Paço e da Consciência e Ordens, encarregou os juízes dos órfãos de entregar os bens dos defuntos e ausentes aos parentes mais próximos e de administrar as habilitações dos herdeiros. Em 1830, a lei de 3 de novembro extinguiu a Provedoria dos Defuntos e Ausentes, confirmando a passagem da administração dos bens destes para a esfera de atuação dos juízes de órfãos.

Uma nota final se impõe sobre a questão do público e privado nos processos de transmissão de bens que acabámos de analisar. No Império, dificilmente se poderia afirmar que esses processos eram de caráter privado, uma vez que

${ }^{61}$ Margarida Durães, Herança e sucessão ..., cit., p.162. 
estavam sob a tutela das instituições da Coroa. Quer as provedorias dos defuntos quer as misericórdias tutelavam os processos de transferência, supostamente no interesse dos herdeiros, cujos bens procuravam salvaguardar (não podemos esquecer que as misericórdias possuíam o estatuto de confrarias leigas sob proteção régia). No entanto, uma vez arrecadados os bens, chegarem ou não aos herdeiros constituía uma lotaria, uma vez que os tempos de espera eram longos, os interesses muitos, e os contextos podiam ser de emergência bélica. Foi este o cenário que se tornou patente nos exemplos que acabámos de fornecer; no entanto, é provável que os dispositivos existentes tivessem funcionado noutros casos, e que os herdeiros tenham recebido as heranças que lhes foram destinadas, inteiras e em tempo útil. Conhecer com detalhe a eficácia deste sistema será um passo numa próxima etapa. 
